\title{
EXPERIENTIAL MARKETING DAN LOYALITAS PADA SMARTPHONE
}

Oleh

Yulfan A. Nurohman

Dosen IAIN Surakarta

\begin{abstract}
Abstrak
Dalam beberapa tahun terakhir, ponsel telah berkembang yang pada awalnya hanya perangkat komunikasi interpersonal menjadi mesin multimedia yang lebih kita kenal dengan sebutan ponsel pintar (Smartphone). Kompetisi diantara merek ponsel pintar (Smartphone), termasuk Samsung semakin meningkat. Untuk memenangkan kompetisi yang dapat dilakukan dengan cara membentuk loyalitas merek dan loyalitas merek dapat dibangun melalui pemasaran experiental. Tujuan dari penelitian ini adalah mempelajari bagaimana pengaruh pemasaran experiental terhadap loyalitas smartphone Samsung. Penelitian ini dilakukan di area Surakarta dengan 155 responden. Teknik sampel yang digunakan dalam penelitian ini adalah metode convenience sampling dan untuk menganalisa data menggunakan metode analisis Structural Equation Model (SEM). Hasil dari temuan ini akan memperjelas hubungan kausal antara variabel yang sedang dikembangkan dalam model penelitian ini. Berdasarkan analisis data diketahui pemasaran experiental secara signifikan dapat mempengaruhi peningkatan loyalitas merek.
\end{abstract}

Kata kunci: Sense, Feel, Think, Act, Relate, pemasaran experiental dan loyalitas merek

\section{PENDAHULUAN}

Evolusi filsafat manajemen pemasaran telah maju dari konsep produksi, konsep produk, konsep penjualan, konsep pemasaran, konsep pemasaran sosial dan konsep hubungan pemasaran menjadi konsep pemasaran experiential. Pemasaran experiential berasal dari konsep pengalaman ekonomi diusulkan oleh Pine dan Gilmore (1998). Menggunakan perspektif jangka panjang, Pine dan Gilmore telah membedakan empat tahapan dalam perkembangan nilai ekonomi yang mengacu pada komoditas, barang, jasa dan pengalaman dan diungkapkan tahap pengalaman ekonomi yang muncul. Pine dan Gilmore mengklaim bahwa sifat persembahan dan atribut kunci kemajuan dari sepadan dan alami (komoditas) ke nyata dan standar (Barang) ke berwujud dan disesuaikan (Layanan) untuk diingat dan pribadi (pengalaman). Penjual- 
pembeli hubungan juga berkembang dari pedagang pasar (komoditas) ke produsenfriendly (Barang) ke penyedia-klien (layanan) untuk aktor-tamu (pengalaman). Seiring dengan ini perkembangan, perusahaan harus menawarkan kepada pelanggan pengalaman yang mengesankan aktif dengan cara menggunakan barang sebagai alat peraga dan jasa sebagai panggung (Pine dan Gilmore, 1998).

Lonjakan penggunaan smartphone di Indonesia dan apalagi penggunaannya yang besar di kalangan mahasiwa mendorong pentingnya memahami penentu yang menciptakan ketergantungan pada smartphone di pasar segmen mahasiwa dan membentuk kemauan orang-orang muda untuk membeli smartphone. Menurut Tien et al. (2009), konsumen dianggap tergantung pada smartphone ketika mereka melihat itu sebagai kebutuhan dan memiliki kecenderungan yang kuat untuk menggunakannya secara terus menerus, merasa terlibat dan enggan untuk terpisah. Setelah digunakan atau telah sangat terlibat dengan smartphone berarti konsumen tidak hanya memiliki pengetahuan pribadi tentang atribut mereka tetapi juga mengalami pengetahuan pribadi tentang bagimana cara kerja bagi para konsumen dan bagaimana mereka memenuhi kebutuhan (Keaveney dan Parathasarathy, 2001).

Perusahaan harus mampu memproduksi dan menawarkan suatu citra dan kepuasan tertentu bagi konsumen dalam lingkup sosial ekonomi agar tetap terjaga keberadaan perusahaan dalam memenuhi pasar sasaran yang diinginkan serta dapat mencapai tujuan yang diharapkan oleh perusahaan. Salah satu yang membuat pelanggan loyal adalah ketika perusahaan mampu menyentuh sisi pengalaman pelanggan. Konsep experiential ini pertama kali dipopulerkan oleh Prof. Bernd H. Schmitt, menurut beliau ada lima elemen yang perlu diperhatikan dalam menarik dan merebut hati pelanggan, kelima elemen itu antara lain sense, feel, think, act dan relate.

Menurut Schmitt (1999) dan Li (2008) dimana experiential marketing dibangun dalam 5 hal yang tercakup dalam Strategic Experiences Modules yaitu sense dipengaruhi oleh sight, sound, taste dan smell; feel dipengaruhi oleh emotion dan feeling; think dipengaruhi oleh convergent, divergent, surprise, intriqu dan provovation; act dipengaruhi oleh interaction, action dan life style; relate dipengaruhi oleh self idealization, others dan culture.

Melalui konsep ini, perusahaan mencoba melibatkan konsumen melalui emosi, perasaan, mendorong mereka untuk berfikir, melakukan tindakan, maupun menjalin 
komunitas. Keberhasilan perusahaan akan tertanam lebih dalam di hati pelanggan menjadi sebuah experiential. Menurut Macfarlane (2008), experiential marketing membawa emosi konsumen untuk menciptakan keputusan pembelian. Menurut Yue et al., (2007) adanya pengaruh positif antara experiential marketing dan loyalitas pada merk dengan melalui aspek-aspek experiential marketing diantaranya sense, feel, think, act dan relate.

Untuk menjawab permasalahan di atas maka perlu dilakukan penelitian tentang experiential marketing terhadap pada loyalitas merek. Sehingga pertanyaan penelitian yang diajukan adalah Apakah aspek-aspek experiential marketing (sense, feel, think, act dan relate) berpengaruh positif terhadap loyalitas merek telepon seluler Samsung.

\section{METODE PENELITIAN}

Penelitian ini dilakukan di kota Surakarta dengan waktu penelitian dimulai bulan November 2015 sampai Juli 2016. Sampel adalah bagian dari populasi yang menjadi subyek sesungguhnya dalam penelitian. Penentuan sampel dilakukan untuk menjelaskan hal-hal yang berkaitan dengan jumlah populasi, jumlah sampel yang diambil, metode pengambilan, lokasi sampel dan responden yang akan dimintai keterangan atas data. Maka dalam penelitian ini menggunakan 155 responden. Teknik yang digunakan dalam penelitian ini adalah convenience sampling (non probability sampling) yaitu sebuah teknik pengambilan sampel yang kriterianya telah ditetapkan sebelumnya. Untuk memperoleh data yang relevan terhadap penelitian ini, maka penulis menggunakan teknik pengumpulan data teknik lapangan yang dilakukan untuk memperoleh data primer sebagai bahan penyusunan penelitian. Teknik pengambilan data meliputi metode dan instrumen pengumpulan data. Sedangkan instrumen merupakan alat bantu yang dipilih dan digunakan oleh peneliti dalam kegiatannya mengumpulkan agar kegiatan tersebut menjadi sistematis dan dapat dipermudah (Arikunto, 1995).

\section{Definisi Operasional}

Definisi operasional variabel merupakan penjabaran akan definisi variabel pada penelitian ini. Selanjutnya definisi operasional merupakan gambaran dari pengukuran atas variabel yang dikembangkan pada penelitian ini. 
a. Sense

Sense adalah pengalaman terhadap kelima indera manusia (pendengaran, penciuman, sentuhan dan pengecapan).

$\mathrm{X}_{1}($ Sight $) \quad$ : Pengalaman dari produk yang dapat dirasakan melalui indera penglihatan

$\mathrm{X}_{2}($ Sound $)$ : Pengalaman dari produk yang dapat dirasakan melalui indera pendengaran

$\mathrm{X}_{3}($ Touch $)$ : Pengalaman dari produk yang dapat dirasakan melalui indera sentuhan

b. Feel

Feel merupakan sebuah pengalaman melalui perasaan, emosi dan suasana hati.

$\mathrm{X}_{4}$ (Feeling) : Pengalaman melalui perasaan dengan rangsangan spesifik dan sifatnya kuat

$\mathrm{X}_{5}$ (Emotion) : Pengalaman yang dihasilkan oleh emosi

$\mathrm{X}_{6}($ Mood $) \quad$ : Pengalaman karena suasana hati atau perasaan yang tidak

c. Think

Think adalah Pengalaman dengan mendorong pelanggan terlibat dalam pemikiran seksama dan kreatif..

$\mathrm{X}_{7}$ (Convergent) : Proses mempersempit fokus seseorang pada beberapa ide atau gagasan manjadi sebuah

$\mathrm{X}_{8}$ (Divergent) : Pemikiran yang memberikan pikiran seseorang yang bergerak kemana-mana secara simultan

$\mathrm{X}_{9}$ (Surprisse) : Memberikan kejutan atau sesuatu lebih dari yang dijanjikan

$\mathrm{X}_{10}$ (Intrique) : Memberikan pengalaman lebih dari kejutan dimana merupakan filosofis dasar dari produk

$\mathrm{X}_{11}$ (Provocation) : Menciptakan pengalaman dengan menggunakan provokasi 
d. Act

Menciptakan pengalaman yang berkaitan dengan perilaku, fisik dan gaya hidup jangka panjang.

$\mathrm{X}_{12}$ (Interaction) : Berhubungan dengan yang lainnya karena berkaitan erat dengan perilaku tubuh dan perilaku sosial dari kegiatan orang yang melakukan interaksi kuat

$\mathrm{X}_{13}$ (Action) : Aksi yang merupakan bagian dari produk atau dilakukan oleh produk

$\mathrm{X}_{14}$ (Lifestyle) : Pengalaman yang ditimbulkan oleh gaya hidup yang melekat pada produk

e. Relate

Menghubungkan diri pribadi seseorang pada konteks sosial budaya yang kemudian menciptakan identitas sosial.

$\mathrm{X}_{15}($ Self-Idealization) $:$ Idealisasi diri dari seseorang terhadap produk

$\mathrm{X}_{16}($ Others $) \quad$ : Kerjasama dengan perusahaan lain atau karena fitur didalamnya

$X_{17}($ Culture) $\quad$ : Pengalaman karena mempunyai gengsi

f. Experiential Marketing

Dimensi variabel Experiential Marketing merupakan adaptasi dari penelitian Wunderman (2003). Indikatornya adalah Performance, Treatment dan Community.

$\mathrm{X}_{18}$ (Performance) : Produk mempunyai tampilan yang lebih baik daripada pesaing

$\mathrm{X}_{19}$ (Treatment) : Interaksi produk dengan konsumen

$\mathrm{X}_{20}$ (Community) : Produk dikenal masyarakat

g. Loyalitas Merek

Berdasarkan pengembangan dari Hamzah (2007) dan Maulani (2009), maka dimensi loyalitas merek terbentuk dari tiga indikator yaitu retention, referrals dan related sales..

$\mathrm{X}_{21}$ (Retention) : Selalu diingat

$\mathrm{X}_{22}$ (Referrals) : Merekomendasikan ke orang lain

$\mathrm{X}_{23}$ (Related Sales) : Melakukan pembelian ulang 


\section{ANALISIS DATA}

Pengujian validitas item-item pertanyaan dalam kuesioner bertujuan mengetahui apakah item-item tersebut benar-benar mengukur konsep-konsep yang dimaksud dalam penelitian ini dengan tepat. Butir-butir pengukuran yang digunakan dalam penelitian ini dan dipandukan dengan penjabaran atas definisi teoritis dari variabel yang digunakan dalam penelitian ini. Dikarenakan syarat untuk dapat menganalisis model dengan SEM, indikator masing-masing konstruk harus memiliki loading factor yang signifikan terhadap konstruk yang diukur maka dalam penelitian ini pengujian validitas instrument yang digunakan adalah Confirmatory Factor Analisys (CFA) dengan bantuan SPSS FOR WINDOWS. Dimana setiap item pertayaan harus mempunyai factor loading yang lebih dari 0,40 (Hair et al., 1998:111).

Uji reliabilitas adalah untuk melihat apakah rangkaian kuesioner yang dipergunakan untuk mengukur suatu konstruk tidak mempunyai kecenderungan tertentu. Nilai yang lazim dipakai adalah 0,6. Perhitungan dengan SPSS sama dengan perhitungan validitas dengan Corrected Item to Total Correlation. Nilai yang dilihat adalah Alpha, pada bagian kiri bawah.

\section{HASIL DAN PEMBAHASAN}

Dalam penelitian ini akan digunakan uji validitas dengan Confirmatory Factor Analysis dengan bantuan software SPSS for windows versi 15, di mana setiap item pertanyaan harus mempunyai factor loading > 0,40. Berdasarkan hasil pengujian validitas diperoleh hasil bahwa terdapat dua item yang memiliki nilai loading faktor tidak mengelompok pada kelompoknya yaitu sense 3, dan experiential marketing 2, hal ini mengindikasikan bahwa kedua item tersebut tidak valid dan harus didrop atau dibuang (reduksi).

Hasil pengujian reliabilitas variabel, dengan menggunakan bantuan Software SPSS For Windows versi 15, didapatkan nilai Cronbach Alpha dari masing-masing variabel pada sampel besar sebagai berikut: 
Tabel Hasil Uji Reliabilitas

\begin{tabular}{|c|c|c|}
\hline Variabel & Cronbach's Alpha & Keterangan \\
\hline Sense & 0,655 & Reliabel \\
\hline Feel & 0,627 & Reliabel \\
\hline Think & 0,708 & Reliabel \\
\hline Act & 0,649 & Reliabel \\
\hline Relate & 0,663 & Reliabel \\
\hline EM (Experiental Marketing) & 0,604 & Reliabel \\
\hline Loyalitas Merek & 0,698 & Reliabel \\
\hline
\end{tabular}

Sumber : Data primer yang diolah oleh peneliti (2011)

Berdasarkan hasil pengujian reliabilitas pada tabel di atas diperoleh hasil dari ketujuh variabel yang diteliti, yaitu sense, feel, think, act, relate, Experiental Marketing, dan brand loyalty (loyalitas merek) memiliki nilai cronbach alpha $>0,60$, yang berarti bahwa intrumen yang diteliti untuk mengungkap ketujuh variabel tersebut dinyatakan layak dijadikan instrumen dalam penelitian ini atau dikatakan reliabel (handal).

Jumlah responden dalam penelitian ini adalah sebanyak 155 responden. Jumlah sampel tersebut merupakan responden yang memenuhi syarat dalam menjawab kuesioner yang diberikan. Syarat yang harus dipenuhi selain kecukupan sampel dalam mengunakan analisis SEM yaitu normalitas data. Berdasarkan hasil pengujian normalitas diketahui secara univariate untuk nilai-nilai dalam C.R skewness, dan C.R kurtosis, tidak terdapat item yang memiliki nilai diatas $\pm 2,58$ yang berarti bahwa secara univariate memiliki sebaran data normal. Nilai yang tertera di pojok kanan bawah pada tabel di atas menandakan bahwa data terdistribusi normal secara multivariate dengan nilai C.R kurtosis 2,112 < 2,58. Dikarenakan secara multivariate dan univariate data terdistribusikan normal, maka pengujian outlier tidak perlu dilakukan. Akan tetapi untuk melengkapi hasil pengujian maka dalam penelitian akan disertakan/ dibahas hasil pengujian outlier selanjutnya. 
Tabel Hasil Pengujian Outlier

\begin{tabular}{rrrr}
\hline Observation number & $\begin{array}{r}\text { Mahalanobis d- } \\
\text { squared }\end{array}$ & p1 & p2 \\
\hline 83 & 33.654 & .029 & .989 \\
140 & 31.519 & .049 & .996 \\
3 & 31.429 & .050 .985 \\
40 & 31.125 & .054 & .969 \\
& $\cdot$ & & \\
\hline
\end{tabular}

Sumber: data primer diolah, 2011

Berdasarkan hasil pada tabel di atas dapat diketahui terdapat indikasi 2 nilai observasi yang mengindikasikan mengalami outlier karena nilai $\mathrm{p} 1<0,05$, sedangkan dari 2 nilai observasi tersebut memiliki nilai p2 $>0,05$. Sehingga dapat disimpulkan bahwa 2 nilai observasi yang mengindikasikan mengalami masalah outlier tersebut masih dapat diterima (tidak terdapat outliers).

Dalam analisis SEM tidak ada alat uji statistik tunggal untuk mengukur atau menguji hipotesis mengenai model (Hair et al., 1995; Joreskog \& Sorbom, 1989; Long, 1983; Tabachnick \& Fidell, 1996 dalam Ferdinand, 2005). Umumnya terhadap berbagai jenis fit index yang digunakan untuk mengukur derajat kesesuaian antara model yang dihipotesiskan dengan data yang disajikan. Berikut ini adalah hasil pengujian indeks kesesuaian dan cut-off valuenya untuk digunakan dalam menguji apakah sebuah model dapat diterima atau ditolak.

Berdasarkan hasil pengujian dengan menggunakan program AMOS 16 diperoleh hasil goodness of fit sebagai berikut: 
Tabel Evaluasi Goodness-of-Fit Indices

\begin{tabular}{lccc}
\hline \multicolumn{1}{c}{$\begin{array}{c}\text { Indeks } \\
\text { Model goodness of fit }\end{array}$} & $\begin{array}{c}\text { Cut-off } \\
\text { Value }\end{array}$ & $\begin{array}{c}\text { Hasil } \\
\text { Model }\end{array}$ & Kesimpulan \\
\cline { 1 - 3 } Chi Square & Diharapkan kecil & 259,298 & \multirow{2}{*}{ Tidak Fit } \\
\cline { 1 - 3 } Probabilitas Chi Square (p) & $\geq 0,05$ & 0,000 & Fit \\
\hline CMIN/DF & $\leq 2,00-3,00$ & 1,581 & \multirow{2}{*}{ Tidak Fit } \\
\cline { 1 - 2 } $\begin{array}{l}\text { Adjusted goodness of fit index } \\
\text { (AGFI) }\end{array}$ & $\geq 0,90$ & 0,785 & Tidak Fit \\
\hline Comparative fit index (CFI) & $\geq 0,95$ & 0,835 & Tidak Fit \\
\hline Tucker-Lewis Index (TLI) & $\geq 0,95$ & 0,809 & Fit \\
\hline $\begin{array}{l}\text { Root mean square error } \\
\text { approximation (RMSEA) }\end{array}$ & $\leq 0,08$ & 0,061 &
\end{tabular}

Sumber: data primer diolah, 2011

Tabel di atas menunjukkan ringkasan hasil yang diperoleh dalam kajian dan nilai yang direkomendasikan untuk mengukur fit-nya model. Seperti yang ditunjukkan dalam tabel di atas, sebagai syarat utama model ML (maximum likelihood) adalah nilai chi-square diharapkan kecil atau nilai probabilitas chi-square $>0,05$, apabila tidak fit atau tidak terpenuhi (nilai goodness of fit yang tidak fit), maka langkah selanjutnya model harus dimodifikasi untuk memperoleh hasil goodness of fit menjadi lebih baik atau terpenuhi.

Dikarenakan sebelumnya model dinyatakan tidak fit maka modifikasi model harus dilakukan dengan cara mengkorelasikan nilai measurement error indikator melalui "modification indices"nya. Adapun hasil modifikasi model selengkapnya adalah sebagai berikut: 


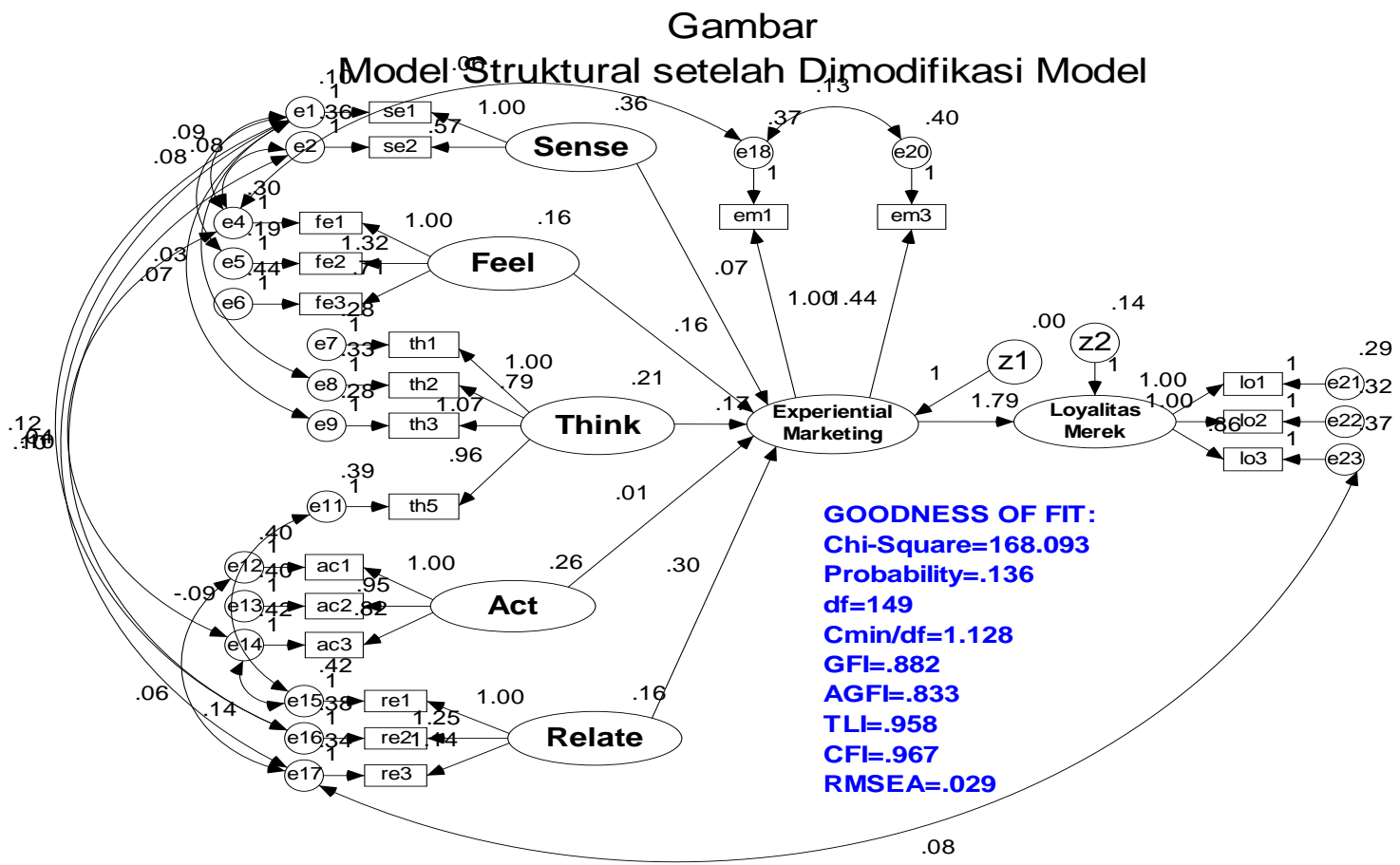

Gambar Model Struktural (SEM) dengan Modifikasi Model

Hasil selengkapnya dari modifikasi model struktural pada gambar di atas akan diuraikan oleh tabel sebagai berikut:

Tabel Evaluasi Goodness-of-Fit Indices setelah Modifikasi

\begin{tabular}{lccc}
\hline \multicolumn{1}{c}{$\begin{array}{c}\text { Indeks } \\
\text { Model Goodness of Fit }\end{array}$} & $\begin{array}{c}\text { Cut-off } \\
\text { Value }\end{array}$ & $\begin{array}{c}\text { Hasil } \\
\text { Model }\end{array}$ & Kesimpulan \\
\hline Chi Square & Diharapkan kecil & 168,093 & Fit \\
Probabilitas Chi Square (p) & $\geq 0,05$ & 0,136 & Fit \\
CMIN/DF & $\leq 2,00$ & 1,128 & Marginal \\
$\begin{array}{l}\text { Adjusted goodness of fit index } \\
\text { (AGFI) }\end{array}$ & $\geq 0,90$ & 0,833 & Fit \\
$\begin{array}{l}\text { Comparative fit index (CFI) } \\
\text { Tucker-Lewis Index (TLI) }\end{array}$ & $\geq 0,95$ & 0,967 & Fit \\
$\begin{array}{l}\text { Root mean square error } \\
\text { approximation (RMSEA) }\end{array}$ & $\leq 0,95$ & 0,958 & Fit \\
\hline
\end{tabular}

Sumber: data primer diolah, 2011 
Tabel di atas menunjukkan ringkasan hasil yang diperoleh dalam kajian dan nilai yang direkomendasikan untuk mengukur fit-nya model. Seperti yang ditunjukkan dalam tabel di atas, nilai chi-square harus fit (nilai probabilitas $>0,05$ ) terpenuhi dengan nilai probabilitas sebesar 0,136>0,05, dan diiringi pengukuran fit model lainnya yang telah dinyatakan fit. Secara overall atau keseluruhan dari enam pengukuran goodness of fit model dinyatakan fit (lima pengukuran fit, hanya satu pengukuran yang marginal).

Hanya satu kriteria yang marginal yaitu adjusted goodnees-of-fit index (AGFI) sedikit lebih kecil dari nilai yang direkomendasikan. Namun, mengikut Salisbury et al. (2001), Cheng, 2001; Hu, dkk (1999), dan Segars \& Grover (1993) dalam Ma'ruf et. al (2002) merekomendasikan AGFI minimum $\geq 0,80$. Dengan demikian, secara overall model yang dikembangkan adalah fit dengan data.

Analisis kausalitas dilakukan guna mengetahui hubungan antar variabel. Pada penelitian ini diharapkan dengan adanya pengujian kausalitas dapat mengetahui pengaruh yang terjadi antara variabel eksogen dengan variabel endogen.

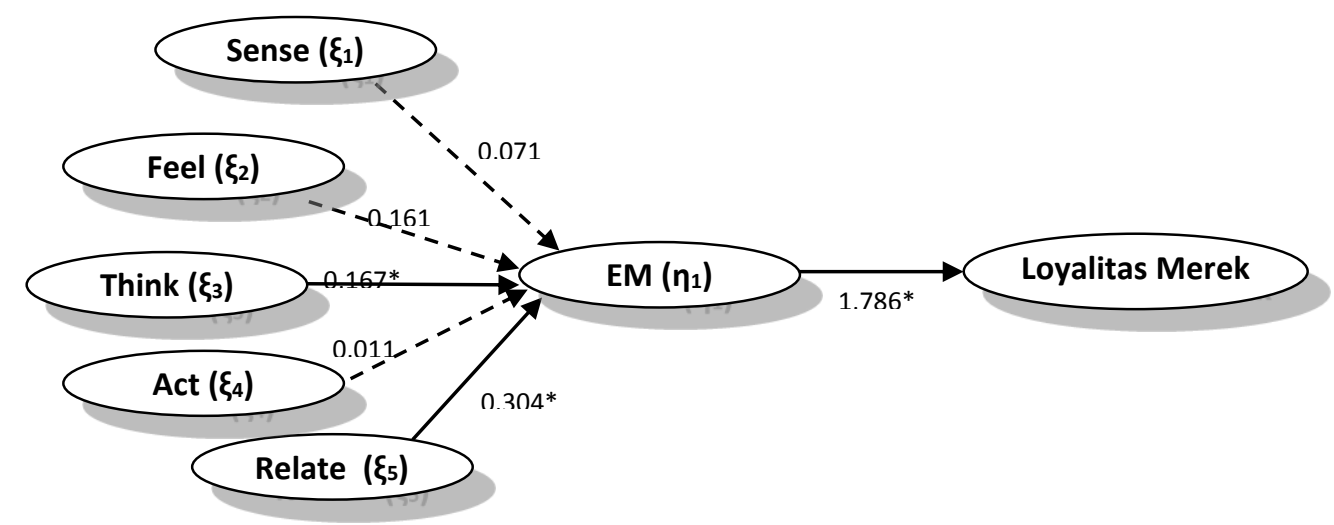

Gambar : Hubungan Kausalitas antar Variabel

\section{Keterangan:}

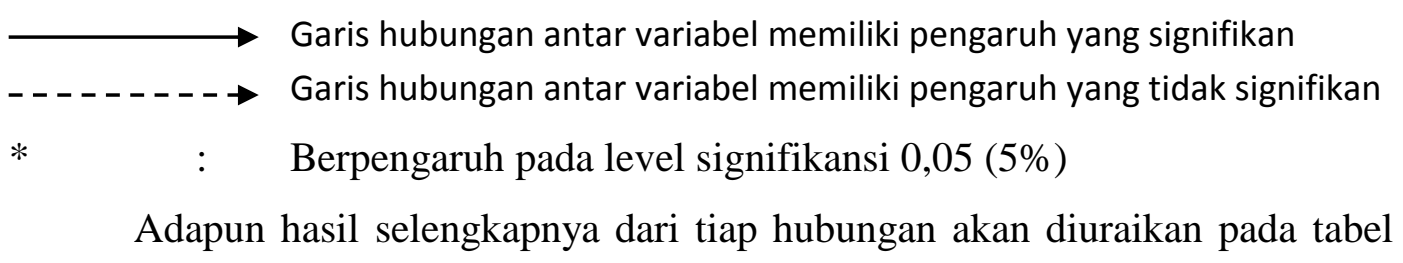
sebagai berikut: 
Tabel Hasil Pengujian Hipotesis

\begin{tabular}{|c|c|c|c|c|}
\hline Hubungan Variabel & Estimate & S.E. & C.R. & $\mathbf{P}$ \\
\hline Experiential_Marketing <--- Sense & .071 & .074 & .963 & .335 \\
\hline Experiential_Marketing <--- Feel & .161 & .084 & 1.923 & .054 \\
\hline Experiential_Marketing<--- Act & .011 & .051 & .215 & .830 \\
\hline Experiential_Marketing <--- Think & .167 & .079 & 2.108 & .035 \\
\hline Experiential_Marketing <--- Relate & .304 & .128 & 2.368 & .018 \\
\hline $\begin{array}{l}\text { Loyalitas_Merek } \quad<---\begin{array}{l}\text { Experiential_ } \\
\text { Marketing }\end{array}\end{array}$ & 1.786 & .747 & 2.393 & .017 \\
\hline
\end{tabular}

Sumber: data primer diolah, 2011

Berdasarkan hasil pengujian kausalitas yang terangkum pada tabel di atas diperoleh hasil bahwa sense tidak berpengaruh signifikan positif terhadap experiential marketing dengan perolehan nilai C.R sebesar 0,963, nilai estimate sebesar 0,071, dan nilai probabilitas sebesar 0,335 >0,05 (pada level signifikansi 5\%).

Berdasarkan hasil pengujian kausalitas yang terangkum pada tabel di atas diperoleh hasil bahwa feel tidak berpengaruh signifikan positif terhadap experiential marketing dengan perolehan nilai C.R sebesar 1,923, nilai estimate sebesar 0,161, dan nilai probabilitas sebesar 0,054 >0,05 (pada level signifikansi 5\%).

Berdasarkan hasil pengujian kausalitas yang terangkum pada tabel di atas diperoleh hasil bahwa act tidak berpengaruh signifikan terhadap experiential marketing dengan perolehan nilai C.R sebesar 0,215, nilai estimate sebesar 0,011, dan nilai probabilitas sebesar $0,830>0,05$.

Berdasarkan hasil pengujian kausalitas yang terangkum pada tabel di atas diperoleh hasil bahwa think berpengaruh signifikan positif terhadap experiential marketing dengan perolehan nilai C.R sebesar 2,108, nilai estimate sebesar 0,167, dan nilai probabilitas sebesar $0,035(*)<0,05$ (pada level signifikansi 5\%).

Berdasarkan hasil pengujian kausalitas yang terangkum pada tabel di atas diperoleh hasil bahwa relate berpengaruh signifikan terhadap experiential marketing dengan perolehan nilai C.R sebesar 2,368, nilai estimate sebesar 0,304, dan nilai probabilitas sebesar $0,018(*)<0,05$ (pada level signifikansi 5\%).

Berdasarkan hasil pengujian kausalitas yang terangkum pada tabel di atas diperoleh hasil bahwa experiential marketing berpengaruh signifikan positif terhadap 
loyalitas merek dengan perolehan nilai C.R sebesar 2,393, nilai estimate sebesar 1,786, dan nilai probabilitas sebesar 0,017 (*) <0,05 (pada level signifikansi 5\%).

\section{Analisis Direct Effect, dan Indirect Effect}

Analisis ini digunakan untuk mengetahui kekuatan pengaruh antara konstruk baik langsung, maupun tidak langsung. Efek langsung (direct effect) tidak lain adalah koefisien dari semua garis koefisien dengan anak panah satu ujung. Efek tidak langsung adalah efek yang muncul melalui sebuah variabel antara. Hasil pengujian model di atas menunjukkan efek langsung, dan efek tidak langsung yang akan diuraikan dalam tabel-tabel berikut ini:

Tabel Direct Effect

\begin{tabular}{lccccccrr}
\hline \multicolumn{1}{c}{ Variabel } & \multicolumn{2}{c}{ Think Relate } & Act & \multicolumn{3}{c}{ Feel Sense $\begin{array}{c}\text { Experiential_ Loyalitas_ } \\
\text { Marketing }\end{array}$} \\
& Merek \\
\hline Experiential_Marketing & .167 & .304 & .011 & .161 & .071 & .000 & .000 \\
Loyalitas_Merek & .000 & .000 & .000 & .000 & .000 & 1.786 & .000 \\
\hline
\end{tabular}

Sumber: data primer diolah, 2011

Tabel di atas menunjukkan bahwa terdapat efek langsung dari think terhadap experiential marketing sebesar 0,167; efek langsung dari relate terhadap experiential marketing sebesar 0,304; efek langsung dari act terhadap experiential marketing sebesar 0,011; efek langsung dari feel terhadap experiential marketing sebesar 0,161; efek langsung dari sense terhadap experiential marketing sebesar 0,071; dan efek langsung dari experiential marketing terhadap loyalitas merek sebesar 1,786.

Berikut ini akan disajikan hasil pengujian efek tidak langsung antar variabel:

Tabel Indirect Effect

\begin{tabular}{lllllllll}
\hline \multicolumn{1}{c}{ Variabel } & \multicolumn{3}{c}{ Think Relate } & Act & Feel Sense & \multicolumn{5}{c}{$\begin{array}{c}\text { Experiential_Loyalitas_ } \\
\text { Marketing }\end{array}$} & Merek \\
\hline Experiential_Marketing & .000 & .000 & .000 & .000 & .000 & .000 & .000 \\
Loyalitas_Merek & .298 & .543 & .019 & .288 & .127 & .000 & .000 \\
\hline Sumber: data primer diolah, 2011 & & & & & &
\end{tabular}

Sumber: data primer diolah, 2011

Tabel di atas menunjukkan bahwa terdapat efek tidak langsung dari think terhadap loyalitas merek sebesar 0,298; efek tidak langsung dari relate terhadap loyalitas merek sebesar 0,543; efek tidak langsung dari act terhadap loyalitas merek sebesar 0,019; efek tidak langsung dari feel terhadap loyalitas merek sebesar 0,288; dan efek tidak langsung dari sense terhadap loyalitas merek sebesar 0,127. 


\section{KESIMPULAN}

Dari hasil pengujian hipotesis dan pembahasan dalam penelitian ini, dapat diambil beberapa kesimpulan antara lain sebagai berikut:

1. Hubungan think dan relate berpengaruh singnifikan terhadap experiential marketing $(\mathrm{p}<0,05)$. Hipotesis ketiga dan kelima dalam penelitian ini terbukti.

2. Hipotesis pertama, kedua, dan keempat dalam penelitian ini tidak terbukti. Hal tersebut dapat diketahui berdasarkan hasil pengujian hipotesis (kausalitas) dimana hubungan ketiga variabel (sense, feel, dan act) terhadap experiential marketing tidak berpengaruh signifikan positif $(\mathrm{p}>0,05)$.

3. Hipotesis keenam dalam penelitian ini terbukti bahwa, experiential marketing dapat berpengaruh signifikan terhadap peningkatan loyalitas merek. Hal tersebut dapat dilihat berdasarkan hasil pengujian dimana nilai probabilitas (p) $<0,05$.

Saran-saran untuk penelitian selanjutnya adalah fokus penelitian harus diperlebar dengan menambah variabel -variabel lain seperti kepuasan pelanggan, kualitas layanan dan loyalitas pelanggan sehingga tercipta model yang lebih komprehensif. Selain itu penambahan objek penelitian dengan tidak hanya menggunakan satu merek yang diteliti sehingga dapat membuat hasil penelitian di bidang experiential marketing lebih bisa digeneralisir.

Bagi pihak Samsung, saran yang dapat diberikan adalah mereka hendaknya lebih memperhatikan faktor-faktor yang dapat berpengaruh terhadap peningkatan experiential marketing sehingga dapat lebih meningkatkan loyalitas merek Samsung pada masyarakat Surakarta. 


\section{DAFTAR PUSTAKA}

Amir, Hamzah, 2007. "Analisis Experiential Marketing, Emotional Branding dan Trust terhadap Loyalitas Merek Mentari” Usahawan No. 06, Tahun XXXVI Juni p. 22-8

Arikunto, Suharsimi, 1996, Prosedur Penelitian Suatu Pendekatan Praktis, Edisi Revisi Enam, Cetakan Ketigabelas, Jakarta :Rineka Cipta

Hadi, Sutrisno, 1997. Metodologi Research; Jilid I, Yogyakarta, Penerbit. Andi Offset.

Hair, Joseph F., Ralph E. Anderson, Ronald L Tatham, and William C. Black, 1995. “Multivariate Data Analysis", 5th ed.Upper Saddle River, NJ: Prentice hall

$\mathrm{Li}$, Chuen Ye, "A Discussion of Applying Experiential Marketing to Leisure Agriculture with AHP" Journal of American Academy of Bussiness Cambridge, Mar 2008: 13, 1 ABI/INFORM Globalpg. 98

Ma'ruf, Jasman J., Ramayah, T., and Mohamed, Osman. 2002. Pengembangan Model Pengukuran untuk Memprediksi Perilaku Niat Menggunakan Media Internet: Suatu Pendekatan Structural Equation Model. The proceedings of The International Seminar, Indonesia-Malaysia, "The Role of Harmonization of Economics and Business Discipline in Global Competitiveness, Banda Aceh, Indonesia 14-15 $5^{\text {th }}$ October 2002.

Macfarlane B., 1998, Refugees, nomads and tourists: an anatomy of business and management lecturers in Higher Education, Journal of European Business Education, 7(2) 37-44

Mira, Maulani, 2009. "Anteseden Experiential Marketing dan Konsekuensinya pada Customers Brand Loyality Motor Yamaha dikota Semarang" Universitas Diponegoro Semarang

Pine, B. J., II, \& Gilmore, J. H. (1998). Welcome to the experience economy. Harvard Business Review, 76(4), 97-105.

Schmitt, Bernd, 1999, Experiential Marketing. The Free Press New York

Sekaran, Uma. 2006. “Research Methods For Bussiness”. Jakarta: Salemba Empat. 